\title{
Reflexões sobre os processos de descentralização da Política Nacional de Alimentação e Nutrição nos seus 20 anos
}

\author{
Reflections on the decentralization processes \\ of the Brazilian National Food and Nutrition \\ Policy in its 20 years
}

\section{Reflexiones sobre los procesos de descentralización de la Política Nacional de Alimentación y Nutrición en sus 20 años}

\author{
Andhressa Araújo Fagundes 1 \\ Jorginete de Jesus Damião 2 \\ Rita de Cássia Lisboa Ribeiro
}

doi: 10.1590/0102-311X00038421

Nesses 20 anos de existência, a Política Nacional de Alimentação e Nutrição (PNAN) se constituiu como fio condutor das ações de alimentação e nutrição no Brasil, norteando as práticas alimentares saudáveis e contribuindo para a construção das políticas voltadas à garantia de direito humano à alimentação adequada (DHAA), processo protagonizado pela ação da sociedade civil, que assumiu espaço na agenda governamental. A existência de uma política nacional de alimentação e nutrição com um arcabouço teórico atualizado e consistente, definição de diretrizes estratégicas e atribuições entre atores envolvidos, e financiamento próprio, possibilitou avanços para a organização das ações de alimentação e nutrição no setor saúde.

A estruturação de uma coordenação federal favoreceu a organização de áreas técnicas de alimentação e nutrição de forma descentralizada nos outros níveis de gestão, principalmente nos estados, ainda que, em muitos casos, sem o reconhecimento formal no organograma institucional. A descentralização dessas ações tem acontecido perante a conformação de uma rede de responsáveis técnicos de alimentação e nutrição. As gestões estaduais realizam a intermediação entre o governo federal e os municípios, com papel de difusão de informações, formação das referências técnicas e monitoramento das ações, enquanto as gestões municipais se responsabilizam pela implementação dos programas nos serviços de sua abrangência e gestão dos recursos transferidos pelo Governo Federal.

Para fortalecer o desenvolvimento da PNAN no nível local, a Coordenação-Geral de Alimentação e Nutrição (CGAN), do Ministério da Saúde, tem diversificado as estratégias de financiamento por meio de repasses de recursos para estados e municípios, e colaboração com instituições de ensino e pesquisa, por intermédio de termos de execução descentralizada, convênios e editais de financiamento. As parcerias com universidades têm ampliado o caráter multidisciplinar, já as Câmaras Intersetoriais de Segurança Alimentar e Nutricional, nos locais onde existem, têm papel determinante na indução da intersetorialidade. Além disso, outros atores da sociedade civil ajudam a qualificar e difundir as agendas estratégicas da alimentação e nutrição.

A gestão nas esferas estadual e municipal ainda é um desafio expressivo, tanto em relação à institucionalização das estruturas de coordenação, quanto em relação à qualificação da coordenação local e à baixa disponibilidade de uma equipe técnica suficiente para implementar e monitorar as ações de alimentação e nutrição. A descontinuidade dos programas por mudanças de gestores é um problema
1 Universidade Federal de Sergipe, São Cristóvão, Brasil.

2 Instituto de Nutrição, Universidade do Estado do Rio de Janeiro, Rio de Janeiro, Brasil.

Correspondência A. A. Fagundes Universidade Federal de Sergipe.

Av. Marechal Rondon $s / n$ São Cristóvão, SE 49100-000, Brasil. afagundes16@gmail.com 
para a capacidade de governança da PNAN, embora não seja uma particularidade desta política no Sistema Único de Saúde (SUS). Igualmente, a precariedade de vínculos de trabalho, sobreposição de atribuições e elevada rotatividade profissional dificultam a continuidade das ações.

Para enfrentar a complexidade do cenário alimentar e nutricional atual, a agenda de alimentação e nutrição no nível local ainda precisa experimentar uma descentralização mais efetiva, que pode ser alcançada pela elaboração e implementação de políticas estaduais e municipais de alimentação e nutrição e normativas próprias que considerem as prioridades e necessidades locais. A construção de políticas locais possibilita inovação face às potencialidades de atuação por meio do conhecimento da realidade do próprio território, incluindo informações epidemiológicas e nutricionais do trabalho em comunidade e parcerias com outros atores públicos e da sociedade civil que atuam em seus territórios. A maior autonomia das áreas técnicas para o uso de recursos também pode contribuir para o alcance de uma descentralização mais efetiva, sendo necessários mecanismos que qualifiquem estas áreas para o uso do fundo de alimentação e nutrição, o financiamento para as ações da PNAN 1. Nem sempre os gestores locais de alimentação e nutrição têm autonomia ou conhecem os processos para a operacionalização desses recursos.

O diálogo sobre alimentação e nutrição com as instâncias de controle social, como os Conselhos de Saúde e os conselhos estaduais ou municipais de segurança alimentar e nutricional (SAN), é crucial. A criação de uma Comissão Intersetorial de Alimentação e Nutrição pelos conselhos municipais e estaduais de saúde é uma recomendação do Conselho Nacional de Saúde que pode colaborar para esse objetivo. A atuação dos conselhos municipais e estaduais é fundamental para a priorização de recursos para as ações de alimentação e nutrição no Plano Municipal e na Programação Anual de Saúde, o que vem sendo impulsionado pelos procedimentos de planejamento e prestação de contas do fundo de alimentação e nutrição. Nas três esferas, a articulação com outros setores governamentais, como educação, economia e agricultura, com os poderes legislativo e judiciário é necessária para a gestão das políticas públicas de alimentação e nutrição, face ao caráter intersetorial das ações de competências concorrentes e responsabilidades compartilhadas entre os diferentes entes.

A gestão e a operacionalização da PNAN têm interface com várias coordenações, pela própria natureza de suas ações. As diretrizes estratégicas da PNAN preveem ações integradas às demais ações de saúde e devem compor o cuidado integral na Rede de Atenção à Saúde (RAS), tendo a atenção primária como coordenadora do cuidado e ordenadora da rede, fato que aponta para a necessidade de uma coordenação única comprometida com a articulação intrasetorial, sob o risco de pulverização e fragmentação das ações. Nesse sentido, a perspectiva da integralidade no cuidado demanda que a organização da atenção nutricional inclua os outros pontos de atenção.

A superação do caráter fragmentado, verticalizado e paralelo dos processos de trabalho das equipes, resultado do modelo de implementação de programas voltados ao enfrentamento de agravos nutricionais, também representa um desafio para a descentralização em direção a um modelo de organização do cuidado em alimentação e nutrição que concretize a perspectiva da integralidade 2.

Nesse sentido, a vigilância alimentar e nutricional é uma ação estratégica para a adequada priorização das ações de alimentação e nutrição pelas equipes de saúde. No entanto, a maior parte dos municípios não utiliza suas informações para o planejamento, gestão e avaliação, ficando restritos à coleta de dados. O Sistema de Vigilância Alimentar e Nutricional (SISVAN) ainda tem uma cobertura populacional muito baixa e está centrado no grupo materno-infantil e famílias do Programa Bolsa Família. A integração das informações do e-SUS com outros sistemas de informação da atenção primária à saúde (APS) pode representar um avanço para a legitimação do SISVAN, mas ainda conta com limitações no registro e na migração dos dados, fato que pode ser decorrente da falta de prioridade da alimentação e nutrição no setor saúde.

Outra estratégia comum nos processos de descentralização é a publicação de materiais técnicos direcionados aos profissionais, visando a subsidiar a implantação dos programas, mesmo sem garantir a qualificação das ações, capacitação dos recursos humanos ou maior grau de implantação dos programas nos municípios ${ }^{3}$. No caso da PNAN, além das publicações, os espaços para a comunicação e o fortalecimento dos gestores sobre os seus papéis foram fundamentais para a descentralização. Ao longo desses 20 anos, a CGAN promoveu encontros nacionais, mostras de trabalhos exitosos, espaços para a troca de experiências, capacitações e formação profissional. 
Na RAS, espaço onde a PNAN se concretiza, fica evidente a extensão da agenda de alimentação e nutrição e seu papel na gênese e cuidado dos principais agravos evitáveis de saúde da população, exigindo que as ações aconteçam em parceria com outros profissionais, por meio do apoio matricial. Os nutricionistas devem ser facilitadores potenciais da qualificação dessas ações, por meio da formação de outros profissionais. A recente extinção do cadastramento e financiamento federal dos Núcleos de Apoio à Saúde da Família (NASF), pela nova Política Nacional de Atenção Básica (PNAB 2017), tem comprometido ainda mais a efetivação dessas ações na APS, enfraquecendo o modelo multiprofissional 4 .

Os 20 anos da PNAN, política pioneira dentre várias outras do setor saúde, mostram uma história de resistência e aprendizados, com novos e antigos desafios. A qualificação da gestão da PNAN nos estados e municípios é central para a efetivação de suas ações nos serviços de saúde, onde a Política de fato acontece. Isso envolve a formação de profissionais, incluindo questões referentes aos processos de compra e definição de orçamento, capacidade de articulação intra e intersetorial, com vínculos estáveis de trabalho. Além disso, localmente é preciso ampliar as experiências de implementação da organização do cuidado de alimentação e nutrição em rede, tendo a vigilância alimentar e nutricional como fio condutor das ações.

\section{Colaboradores}

A. A. Fagundes, J. J. Damião e R. C. L. Ribeiro colaboraram na aquisição, análise e interpretação de informações para o trabalho, redação, revisão crítica do conteúdo e aprovação final da versão a ser publicada.

\section{Informações adicionais}

ORCID: Andhressa Araújo Fagundes (0000-00034085-3270); Jorginete de Jesus Damião (0000-00016591-3474); Rita de Cássia Lisboa Ribeiro (00000002-0000-1404).

\section{Agradecimentos}

Agradecemos a todos que contribuíram para a elaboração deste artigo, especialmente às Coordenações Estaduais de Alimentação e Nutrição do Mato Grosso do Sul, Pará, Pernambuco, Rio de Janeiro e Rio Grande do Sul, e às Coordenações Municipais de Altamira, Amambaí, Búzios, Itaperuna, Magé, Nova Prata, Paulista, Recife e Vassouras, cujas reflexões nos encontros realizados em maio de 2020, com os respectivos responsáveis técnicos, colaboraram substancialmente com as autoras. 
1. Pires ACL, Ramos MKP, Alves MFM, Alba RD, Bortolini GA, Silva JRM. Um olhar para as experiências de Alimentação e Nutrição do Prêmio APS Forte. APS em Revista 2020; 2:285-97.

2. Jaime PC, Coitinho DC, Campello T, Silva DO, Santos LMP. Um olhar sobre a agenda de alimentação e nutrição nos trinta anos do Sistema Único de Saúde. Ciênc Saúde Colet 2018; 23:1829-36.
3. Machado PMO. Atenção nutricional no âmbito da atenção primária à saúde: análise de implantação em municípios brasileiros [Tese de Doutorado]. Santa Catarina: Universidade Federal de Santa Catarina; 2018.

4. Giovanella L, Franco CM, Almeida PF. National primary health care policy: where are we headed to? Ciênc Saúde Colet 2020; 25:1475-82.

Recebido em 18/Fev/2021

Versão final reapresentada em 08/Mai/2021

Aprovado em 14/Jun/2021 